\title{
ACOUSTIC STIMULATION INCREASES PHOSPHOINOSITIDE BREAKDOWN IN THE GUINEA PIG COCHLEA
}

\author{
TOSHIYUKi ONO* and JoChen SCHACHT $\dagger$ \\ Kresge Hearing Research Institute, University of Michigan, Ann Arbor, MI 48109-0506, U.S.A.
}

(Received 16 August 1988; accepted 3 October 1988)

\begin{abstract}
The effect of sound stimulation on phosphoinositide turnover was investigated in the inner ear of the guinea pig. The perilymphatic spaces of the cochlea were perfused with $\left[{ }^{32}\right.$ P]orthophosphate $\left({ }^{32} \mathbf{P}_{\mathrm{i}}\right)$ and labeled lipids analyzed in the tissues of the lateral wall of the cochlea (stria vascularis and spiral ligament) and the basilar membrane (organ of Corti). Consistent with previous results, polyphosphoinositides rapidly incorporated ${ }^{32} \mathrm{P}_{\mathrm{i}}$ comprising $70-80 \%$ of labeled lipids in all tissues analyzed: phosphatidylinositol 4,5-bisphosphate (PtdInsP ${ }_{2}$ ) was $66 \%$ of total [ ${ }^{32} \mathrm{P}$ ]phospholipids in the lateral wall tissues and $45 \%$ in the organ of Corti; phosphatidylinositol 4-phosphate (PtdInsP) was $28 \%$ in the lateral wall and $24 \%$ in the organ of Corti. After $90 \mathrm{~min}$ of labeling the hydrolysis of lipids was measured by replacing the radioactive $P_{i}$ with $1 \mathrm{mM} \mathrm{NaH}{ }_{2} P_{4}$ in the perfusate for the $30 \mathrm{~min}$ "chase". Exposure of the ear to sound ( $100 \mathrm{~dB}$ white noise) during the chase significantly augmented the hydrolysis of [ $\left.{ }^{32} \mathrm{P}\right] \mathrm{Ptd}$ Ins $\mathrm{P}_{2}$ in the organ of Corti by $20 \%(P=0.01)$ but not in the lateral wall tissues. Since the organ of Corti contains the auditory sensory cells, the results suggest that the observed increased hydrolysis of PtdInsP $\mathrm{P}_{2}$ is associated with auditory processing in the inner ear.
\end{abstract}

Auditory processing in the mammalian cochlea involves two distinct populations of sensory cells, the inner and the outer hair cells. The inner hair cells are thought to be the primary transducers of acoustic information while the outer hair cells may modulate the micromechanical response of the cochlea by an active motile process in response to efferent activation (Kim, 1984). Contractile movements have indeed been observed in isolated outer hair cells in vitro in response to electrical and chemical stimuli (Brownell, 1984; Zenner et al., 1985).

We have previously investigated phospholipids in auditory receptors. Sound increased ${ }^{32} \mathrm{P}_{j}$-incorporation into phosphoinositides in the ear of the noctuid moth, an effect associated with the action potential (Kilian and Schacht, 1980) while the guinea pig cochlea did not reveal changes in the synthesis of ${ }^{32}$ P-lipids in response to acoustic stimuli (Schacht, 1984). A dynamic role of phospholipids in receptormediated cellular responses was first proposed about 30 years ago (Hokin and Hokin, 1953) but only recently have details of this signal transduction

\footnotetext{
*Permanent address: Department of Otolaryngology, Kyoto Prefectural University of Medicine, Kyoto, Japan. +To whom correspondence should be addressed.
}

N.C.I. $14 / 3-0$ process been elucidated. PtdInsP $P_{2}$ is hydrolyzed to diacylglycerol and inositol trisphosphate, as the initiation of a cascade controlling a variety of cellular processes (Nishizuka, 1984; Berridge and Irvine, 1984; Berridge, 1984) including sensory transduction in photoreceptors (Brown et al., 1984; Fein et al., 1984).

The present study was prompted by the recent suggestions of phosphoinositide involvement in the function of outer hair cells based on the observation that inositol trisphosphate induced motility in these cells in vitro (Schacht and Zenner, 1987). We examine here the effect of sound stimulation on the hydrolysis of PtdIns $P_{2}$ in the guinea pig cochlea in order to determine whether acoustic processing alters phosphoinositide turnover in auditory sensory tissues.

\section{EXPERIMENTAL PROCEDURES}

Pigmented guinea pigs received an intraperitoneal injection of pentobarbital $(20 \mathrm{mg} / \mathrm{kg})$ and an intramuscular injection of innovar $(0.5 \mathrm{ml} / \mathrm{kg})$. The trachea was cannulated for artificial respiration, the left bulla was opened by a conventional ventral approach and perilymphatic perfusions performed as described previously (Nutall et al., 1977; Takada and Schacht, 1982). In brief, a hole was drilled into the scalae tympani and vestibuli of the basal turn of the cochlea. Glass capillaries connected to PE-60 tubing were 
cemented into the holes, and the perilymphatic spaces were perfused with artificial perilymph containing $130 \mathrm{mM} \mathrm{NaCl}$, $5 \mathrm{mM} \mathrm{KCl}, 1 \mathrm{mM} \mathrm{CaCl}, 2 \mathrm{mM} \mathrm{MgCl}, 0.1 \mathrm{mM} \mathrm{NaH} 2 \mathrm{PO}_{4}$, $10 \mathrm{mM} \mathrm{NaHCO}, 5 \mathrm{mM}$ glucose and $10 \mathrm{mM}$ HEPES, find pH 7.4. A constant flow rate of approx. $30 \mu \mathrm{l} / \mathrm{min}$ was obtained by adjusting the heights of inlet and outlet tubing. White noise was delivered through an earphone to the ear canal and the cochlear microphonic potential (CM) was recorded from a stainless steel wire in the inlet capillary. A 15-min perfusion allowed the system to stabilize.

For lipid labeling a perfusate additionally containing $100 \mu \mathrm{Ci}\left[{ }^{32} \mathrm{P}\right]$ orthophosphate $\left({ }^{32} \mathrm{P}_{\mathrm{i}}\right) / \mathrm{ml}$ was applied to the cochlea for $30 \mathrm{~min}$. Thereafter, the flow was stopped and the perfusate allowed to remain in the cochlea for various lengths of time. Throughout these procedures, sound of specified intensity was delivered through the ear phone. At the end of the experiment, the perilymphatic space was perfused with $10 \%$ neutralized formaldehyde and the temporal bone was fixed in the same solution. This procedure provides for efficient preservation and recovery of cochlear phosphoinositides (Orsulakova ot al. 1976).

To study the hydrolysis of phosphoinositides, the cochlea was perfused with ${ }^{32} \mathrm{P}_{\mathrm{i}}$ for 30 min and incubated for an additional $60 \mathrm{~min}$ as described above while white noise $(70 \mathrm{~dB})$ was delivered. After these $90 \mathrm{~min}$, a "chase" perfusion with artificial perilymph containing $1 \mathrm{mM} \mathrm{NaH} \mathrm{PO}_{4}$ and no radioactivity was initiated. At the same time, the sound was changed from $70 \mathrm{~dB}$ to either "silence" (sound off) or intense noise (" $100 \mathrm{~dB}$ "). The experiment was terminated as specified above.

Microdissection of inner ear tissues was performed in $10 \%$ neutralized formaldehyde. The lateral wall of the cochlear duct (stria vascularis, spiral ligament, spiral prominence) and the organ of Corti (hair cells, supporting cells, nerve fibers) were dissected from all turns. Lipids were extracted and identified essentially as described before (Orsulakova et al., 1976; Schacht, 1981). Tissues were homogenized three times in $0.5 \mathrm{ml}$ of chloroform-methanol $(1: 2, \mathrm{v} / \mathrm{v})$ and $0.5 \mathrm{ml}$ of a guinea pig brain homogenate $(20 \% \mathrm{w} / \mathrm{v})$ was added as a source of unlabeled carrier lipids. After the addition of $1.0 \mathrm{ml}$ of chloroform and $0.5 \mathrm{ml} 2.4 \mathrm{~N} \mathrm{HCl}$, mixing and centrifugation, the lower phase was collected and the upper phase was re-extracted with $1.0 \mathrm{ml}$ of chloroform. The combined lower phases were washed with $2.0 \mathrm{ml}$ of methanol$0.5 \mathrm{~N} \mathrm{HCl}(2: 3, \mathrm{v} / \mathrm{v})$ and the upper phase counted for total radioactivity. A portion of the lower phase $(0.2 \mathrm{ml})$ was removed for the determination of total lipid radioactivity, the rest was dried under $\mathrm{N}_{2}$. For separation, the lipids were taken up in $50 \mu \mathrm{l}$ of chloroform and applied to a TLC plate (Merck Silica 60). Lipids were separated in chloroform : methanol: $14 \mathrm{~N}$ ammonia: water $(45: 45: 3.5: 11)$ and located by radioautography and ninhydrin reaction. They were identified by their $R_{\text {. }}$ and cochromatography with known standards (Sigma, St Louis, Mo., U.S.A.). Radioactive lipids were scraped off the TLC plate and their radioactivity determined in a scintillation counter.

\section{RESULTS}

Prior to testing the effect of sound on phospholipid hydrolysis, the time course of labeling of cochlear phosphoinositides by ${ }^{32} \mathrm{P}_{i}$ was established (Fig. 1). PtdInsP $\mathrm{P}_{2}$ and PtdInsP were rapidly labeled in both tissue preparations, reaching maximal incorporation at $60 \mathrm{~min}$ in the organ of Corti and at $90 \mathrm{~min}$ in the lateral wall. Phosphatidate (Ptd) and phosphatidylinositol (PtdIns) were detectable at all times but incorporated ${ }^{32} \mathrm{P}$ at a slower rate. After $90 \mathrm{~min}$ the relative distribution of ${ }^{32} \mathrm{P}$-label in the phospholipids of the organ of Corti was, PtdIns $\mathrm{P}_{2} 45 \%$, PtdInsP $24 \%$, Ptdins $16 \%$ and Ptd $8 \%$ of total label. In the lateral wall tissues, the distribution was PtdIns $\mathrm{P}_{2} 60 \%$, PtdInsP 24\%, PtdIns 11\% and Ptd 5\%. Phosphatidyl ethanolamine (PtdEth) and phosphatidyl choline (PtdCho) achieved a significant ${ }^{32} \mathrm{P}$-content only at later times (Table 1). During the incubation, the CM in response to a sound exposure of moderate intensity $(70 \mathrm{~dB})$ was stable at about $300 \mu \mathrm{V}$ indicating that the procedure did not damage the auditory structures.

The effect of sound on the hydrolysis of the labeled lipids was investigated by continuing the perfusion after $90 \mathrm{~min}$ with a phosphate "chase". Concomitantly, the sound exposure was changed to intense noise or quiet: at $100 \mathrm{~dB}$ the $\mathrm{CM}$ increased to about $480 \mu \mathrm{V}$ and then gradually decreased; in the absence of sound the $\mathrm{CM}$ fell to about $45 \mu \mathrm{V}$. To reduce the intra-animal variability in the results of these in vitro perfusion experiments, the relative distribution of ${ }^{32} \mathrm{P}$ in the lipids was adopted as a measure of hydrolysis. Sound exposure significantly affected the ${ }^{32} \mathrm{P}$-content of polyphosphoinositides in the organ of Corti. After the chase these lipids constituted about $35 \%$ (PtdIns: $\mathrm{P}_{2}$ ) and 17\% (PtdInsP), respectively, of total label in the absence of sound (Table 1). In the presence of sound of $100 \mathrm{~dB}$ the relative PtdIns $\mathrm{P}_{2}$ content was reduced to $28 \%(P=0.01)$. Other lipids showed only non-significant shifts in their distribution. The effect was confirmed by a second measure, the ratio of PtdInsP $P_{2}$ to non-inositide lipids. This ratio, calculated within each experiment, also showed a significant difference $(P<0.001)$ between the quiet and noiseexposed ("100 dB") groups in the organ of Corti (Table 1). Sound did not alter the lipid distribution in the lateral wall tissues.

\section{DISCUSSION}

The results indicate that sound stimulation increases the hydrolysis of PtdIns $P_{2}$ in the organ of Corti of the inner ear. The effect was specific for this lipid and selective for the cochlear structure containing the sensory cells and was not seen in the tissues of the adjacent lateral wall which contains non-sensory elements. This implies that the observed effect is related to the processing of sensory information and that it represents the involvement of the phosphoinositide second messenger system in auditory transduction. 


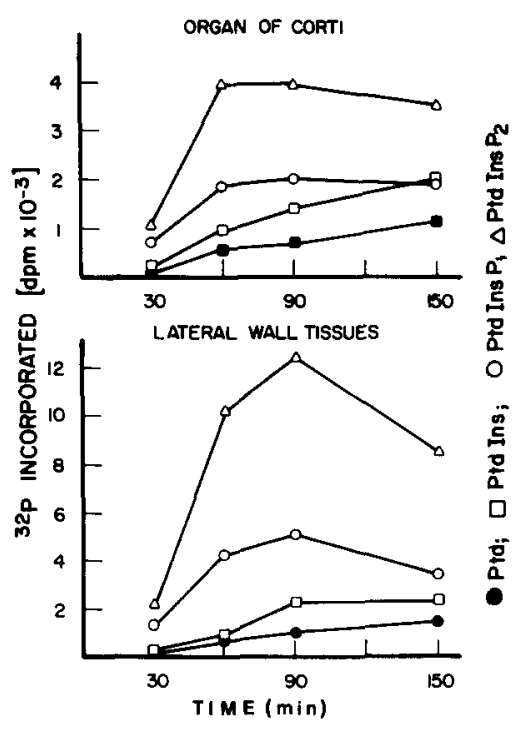

Fig. 1. Time-course of labeling of cochlear phosphoinositides by ${ }^{32} \mathrm{P}_{\mathrm{i}}$. Guinea pigs received a perilymphatic perfusion with $100 \mu \mathrm{Ci}{ }^{32} \mathrm{P}_{\mathrm{i}} / \mathrm{ml}$ as described in Experimental Procedures. The isotope was introduced into the cochlea for $30 \mathrm{~min}$ after which the first time point was taken. The ${ }^{32} \mathrm{P}_{\mathrm{j}}$ then remained in the cochlea for up to a total of $150 \mathrm{~min}$ from the start of the perfusion. Numbers are means from 3 or 2 animals. Organ of Corti includes the hair cells, supporting cells and nerve fibers; lateral wall includes stria vascularis, spiral ligament and spiral prominence.

The pattern of incorporation of ${ }^{32} \mathrm{P}$ into inner ear lipids, namely a high radioactivity in polyphosphoinositides, is consistent with previous studies of cochlear lipids using somewhat different techniques (Orsulakova et al., 1976). Such a pattern is commonly observed in nervous or secretory tissue, for example, brain (Sheltawy and Dawson, 1969; Soukup et al., 1978), peripheral nerve (Bell et al., 1982), kidney (Schibeci and Schacht, 1977) and retina (Abdel-Latif et al., 1985) as well as erythrocytes (Marche et al., 1983). It reflects the rapid metabolic turnover rather than the chemical concentration of these trace lipids (Michell, 1986).

The organ of Corti preparation analyzed contains both inner and outer hair cells and their corresponding innervation. Thus, two possible sites for the effect can be discussed: afferent stimulus processing at the level of the inner hair cells and efferent modulation at the outer hair cells. The inner hair cells possess $95 \%$ of the afferent nerve fiber connections and little or no efferent innervation. They are the primary receptors that respond to acoustic stimulation by depolarization and release of transmitter leading to action potentials in the auditory nerve. Localization of the observed effect to these structures would correspond to our previous results in the ear of the Noctuid moth where a "phosphoinositide effect" correlated with the sound-induced action potential (Kilian and Schacht, 1980). On the other hand, outer hair cells are a potential alternative or additional site of the increased phosphoinositide breakdown. Outer hair cells receive rich efferent innervation suggested to modulate the transduction process by eliciting motile responses in these cells. The primary effector should be the efferent transmitter, presumed to be acetylcholine which may be coupled to the phosphoinositides as second messengers. Supporting this assumption is the fact that calcium as well as inositol trisphosphate can elicit contractions in permeabilized outer hair cells in vitro (Zenner et al., 1985; Schacht and Zenner, 1987). Preliminary experiments (Ono and Schacht, 1987) also suggest that the cholinergic agonist carbamylcholine may enhance the hydrolysis of cochlear phosphoinositides. Further detailed biochemical and pharmacological analyses will be needed to resolve the question whether afferent or efferent auditory processing or both engage the phosphoinositides as a second messenger system.

Acknowledgement-This work was supported by program project grant NS-05785 from the National Institutes of Health.

Table 1. Effect of sound on hydrolysis of ${ }^{32}$ P-lipids

\begin{tabular}{|c|c|c|c|c|c|c|c|c|}
\hline \multirow[b]{2}{*}{ Tissue } & \multirow[b]{2}{*}{ Condition } & \multirow[b]{2}{*}{ PtdIns $_{2}$} & \multirow[b]{2}{*}{ PtdInsP } & \multirow[b]{2}{*}{ PtdIns } & \multirow[b]{2}{*}{ Ptd } & \multirow[b]{2}{*}{ PtdEth } & \multirow[b]{2}{*}{ PtdCho } & \multirow{2}{*}{$\begin{array}{c}\text { PtdInsP }_{2} \dagger \\
\begin{array}{c}\text { non-inositol } \\
\text { lipids }\end{array} \\
\end{array}$} \\
\hline & & & & & & & & \\
\hline & \multicolumn{8}{|c|}{ ( $\%$ of total ${ }^{32} \mathrm{P}$-Lipids) } \\
\hline Organ of Corti & Silence & $34.8 \pm 3.1$ & $17.6 \pm 3.9$ & $25.3 \pm 2.3$ & $7.3 \pm 3.2$ & $8.2 \pm 4.6$ & $7.5 \pm 3.0$ & $1.6 \pm 0.3$ \\
\hline Organ of Corti & $100 \mathrm{~dB}$ & $27.7 \pm 4.8^{*}$ & $16.3 \pm 1.5$ & $27.9 \pm 3.2$ & $7.1 \pm 2.9$ & $11.7 \pm 4.1$ & $9.7 \pm 3.3$ & $1.0 \pm 0.2^{* *}$ \\
\hline Lateral wall & Silence & $52.4 \pm 3.6$ & $16.4 \pm 3.6$ & $17.1 \pm 3.6$ & $5.7 \pm 3.0$ & $3.1 \pm 1.7$ & $5.3 \pm 1.7$ & $3.9 \pm 1.0$ \\
\hline Lateral wall & $100 \mathrm{~dB}$ & $47.3 \pm 5.3$ & $16.5 \pm 2.2$ & $19.9 \pm 2.9$ & $4.5 \pm 2.8$ & $4.7 \pm 1.8$ & $7.2 \pm 2.4$ & $3.0 \pm 0.8$ \\
\hline
\end{tabular}




\section{REFERENCES}

Abdel-Latif A. A., Smith J. P. and Akhtar R. A. (1985) Polyphosphoinositides and muscarinic cholinergic and $\alpha_{1}$-adrenergic receptors in iris smooth muscle. In: Inositol and Phosphoinositides (Bleasdale J. E., Eichberg J. and Hauser G., eds), pp. 275 298. Humana Press, Clifton, N.J.

Bell M. E., Peterson R. G. and Eichberg J. (1982) Metabolism of phospholipids in peripheral nerve from rats with chronic streptozotocin-induced diabetes: increased turnover of phosphatidylinositol-4, 5-bisphosphate. $J$. Neurochem. 39, 192-200.

Berridge M. J. (1984) Inositol trisphosphate and diacylglycerol as second messengers. Biochem. $J$. 220, 345-360.

Berridge M. J. and Irvine R. F. (1984) Inositol trisphosphate. a novel second messenger in cellular signal transduction. Nature 312, 315 321.

Brown J. E., Rubin L. J., Ghalayini A. J., Tarver A. P.. Irvine R. F., Berridge M. J. and Anderson R. E. (1984) Myo-inositol polyphosphate may be a messenger for visual excitation in Limulus photoreceptors. Nature 311, 160-163.

Brownell W. E. (1984) Microscopic observations of cochlear hair cell motility. Scanning Electron. Microse. III, 1401 . 1406.

Fein A., Payne R., Corson W., Berridge M. J. and Irvine R. F. (1984) Photoreceptor excitation and adaptation by inositol 1.4.5-trisphosphate. Nature 311, 157.160.

Hokin M. R. and Hokin L. E. (1953) Enzyme secretion and the incorporation of $\mathrm{P}^{32}$ into phospholipids of pancreas slices. J. biol. Chem. 203, 967977.

Kilian P. L. and Schacht J. (1980) Sound stimulates labeling of polyphosphoinositides in the auditory organ of the noctuid moth. $J$. Neurochem. 34, 709-712.

Kim D. O. (1984) Functional roles of the inner- and outerhair cell subsystems in the cochlea and brain stem. In: Hearing Science (Berlin C. I.. ed.), pp. 241 262. CollegeHill Press, San Diego, Calif.

Marche P., Koutouzov S. and Girard A. (1983) Impairment of membrane phosphoinositide metabolism by aminoglycoside antibiotics: streptomycin, amikacin, kanamycin, dibekacin, gentamicin and neomycin. J. Pharmac, exp. Ther. 227, $415-420$.
Michell R. H. (1986) Inositol lipids and their role in receptor function: history and general principles. In: Phosphoinositides and Receptor Mechanisms (Putney J. W. cd.). pp. I 24. Alan R. Liss, New York

Nishizuka Y. (1984) Turnover of inositol phospholipids and signal transduction. Science 225, 13651370.

Nutlall A. L., Marques D. M. and Lawrence M. (1977) Effects of perilymphatic perfusion with neomycin on the cochlear microphonic potential in the guinea pig. At/a Otolaringol. 83, 393400

Ono T.. and Schacht J. (1987) Effect of cholinergic agents on phospholipid metabolism in the guinea pig cochlea. Audiol., Japan 30, 607608

Orsulakova A., Stockhorst E. and Schacht J. (1976) Effect of neomycin on phosphoinositide labeling and calcium binding in guinea pig inner ear tissues in tito and in vitro. I. Neurochem. 26, 285290.

Schacht J. (1981) Extraction and purification of polyphosphoinositides. In: Mothods in Enzlmology (Colowick S. P. and Kaplan, N. O., eds), Vol. 72D, pp. 626 631. Academic Press, New York.

Schacht J. (1984) Phosphoinositides in the auditory system. In: Transmembrane Signalling and Sensation (Oosawa F.. ed.), pp. 89. 97. Japan Societies Press, Tokyo.

Schacht J. and Zenner H. P. (1987) Evidence that phosphoinositides mediate motility in cochlear outer hair cells. Hearing Res. 31, 155160.

Schibeci A. and Schacht J. (1977) Action of neomycin on the metabolism of polyphopshoinositides in the guinea pig kidney. Biochem. Pharmac. 26, 1769-1774.

Sheltawy A. and Dawson R. M. C. (1969) The deposition and metabolism of polyphosphoinositides in rat and guinea pig brain during development. Biochem. J. 111 , 147154.

Soukup J. F.. Friedel R. O. and Schanberg S. M. (1978) Microwave irradiation fixation for studies of polyphosphoinositide metabolism in brain. J. Neurochem. 30, 635637.

Takada A. and Schacht J. (1982) Calcium antagonism and reversibility of gentamicin-induced loss of cochlear microphonics in the guinea pig. Hearing Res. 8, 179 186.

Zenner H. P., Zimmermann U. and Schmitt U. (1985) Reversible contraction of mammalian cochlear hair cells. Hearing Res. 18, 127133. 